\title{
Review
}

\section{Diet of schoolchildren as a risk factor of nutritional disorders}

\author{
Feruza Kochkorova, Marina Esenamanova, Tatyana Tsivinskaya \\ Department of Hygiene Disciplines, I.K. Akhunbaev Kyrgyz State Medical Academy, Bishkek, Kyrgyzstan
}

\begin{abstract}
In this paper, we present the literature review on nutrition disorders in schoolchildren. as well as the data about the role of rational and balanced nutrition in strengthening of child and adolescent health. We provided the review of literature on the approaches in education facilities on healthy diet education and school meals.
\end{abstract}

Keywords: health, rational and balanced diet, nutritional disorders, children and adolescents, proteins, fats, carbohydrates, vitamins, energy consumption, minerals

(Heart Vessels and Transplantation 2018; 2: doi: 10.24969/hvt.2017.40)

\section{Introduction}

The problem of an individual's health within the context of human rights is gaining more and more importance. The problems regarding the health of children should not depend on the political situation within a country, and without its resolution the country has no future (1). The European strategy "The health of children and adolescents" sees the duty of preserving the health of the growing generation as an investment to the main resource of public development (2).

The school age remains to be the key period in human body development. The real responsibilities of a school are; intellectual development, formation of moral feelings, as well as the care for children's' health. All of these are possible if; there is a healthy environment within the teaching institution, psychological comfort of the educator and the student, systematically organized educational work regarding the formation of healthy lifestyle, rational and balanced diet (3).

The nutrition of these age groups (child and adolescents) is based on sustaining the harmonic growth and development of the organism, optimal work capacity, adaptation to the effects of adverse environmental factors, normalization of metabolic processes, because at this age the child's organism undergoes drastic changes. At school age, the formation of the skeleton is completed and there are changes in the body mass, and neuro-psychology (4).

Therefore, of particular interest is the study of nutrition of school-age children. In addition, in modern conditions, the health of young people as a whole continues to deteriorate (5-19).

Nutrition is one of the main factors that affect the child's health (3). Sufficiency of nutrition is the most important factor in the formation of physical development, nutritive status and health of the child, rational nutrition ensures normal growth and development of the organism, promotes the prevention of various diseases (5-7). The quality of life of the child depends on the nutritional value of consumed food by children as well as their ability to tolerate critical situations (diseases, injuries, surgeries, stress, war and disasters) (8-11). Irrational unbalanced diet in children can cause malnutrition, stunting and overweight, obesity associated with increased morbidity and even mortality (7-11).

Address for Correspondence: Feruza Kochkorova, Department of Hygiene Disciplines, Kyrgyz State Medical Academy IK Akhunbaev, Bishkek, Kyrgyzstan. Email: feruza.k71@mail.ru

Received: 4.10.2017 Revised: 4.11.2017, 5.01.2018 Accepted: 16.01.2018

Copyright@2017 Heart Vessels and Transplantation 
Several survey studies have demonstrated high rate of malnutrition among children in developing countries with reported rates in Africa for stunting was $57.7 \%$ and underweight - $28.8 \%$ (11). Malnutrition of children contributes to the mortality causes in $57 \%$ of children deaths $(12,13)$. In study of Bain et al. (12), protein energy deficiency and micronutrient deficiencies were shown to play major role in the morbidity among children; the main aggravating factors were poverty, poor social factors, low education level, and food insecurities. On the other hand, the children from wealthy social-economic status families turned to have higher obesity and overweight rates, and stunting was characteristic for poorest households (14). A significant part of children population worldwide suffers from malnutrition and $49 \%$ of 10,000000 deaths among children younger 5 years of age in developing countries were attributed to malnutrition (15). In developed countries, overweight and obesity among children is reported to be as high as $17 \%$ (16). The arterial hypertension and emotional mental health disorders are associated with unhealthy diet $(17,18)$.

The malnutrition is more often observed in girls than in boys, malnourished children of female gender are shown to be more prone to food insecurities, weaker learning performance at school and higher morbidity and mortality (19-21). Poverty has been associated with poor food securities causing infectious parasitic diseases and aggravating malnutrition of children (22, 23).

Adequate and rational nutrition is one of the factors playing a key role in maintaining resistance to infections and other unfavorable factors $(4,24)$.

The nutrition of the child should be balanced depending on the age, sex, climate, geographical area of residence and the level of physical activity. In the organization of nutrition, the nutrition regime, the correct distribution of the diet according to meals, is of great importance (25-28).

The metabolism, determines the multifaceted effect of nutritional factors on the health and ability to work of a person. According to the "concept of balanced nutrition" (27), for normal function of organism, not only nutrition is necessary, providing sufficient energy in quantitative terms, but also complex relationships between numerous irreplaceable nutritional factors must be present, each of which has a specific role in metabolism. Nutrition is a factor contributing to the formation of optimal nutritional status and health of the population not only in present time but also in the future, providing optimal physical and neurological development of the adolescent and sufficient immunological resistance $(28,29)$. The quality of nutrition depends not only on the composition and quantity of consumed products, but also on the characteristics of the ecological niche and the anthropological data of the individual; impairments in the structure and quality of nutrition can potentiate negative impact of environmental factors, including factors of social significance $(27,30,31)$.

Specific features of the dietary habits of the population of our republic include the deficiency of animal proteins, vitamins, microelements, dietary fiber, polyunsaturated fatty acids, an excess of simple carbohydrates and animal fat (32).

Inadequate supply of macro- and micronutrients leads to enzymatic and hormonal deficiency, a decrease in immunity and adaptive reserves of the body, which is manifested by an increase in the incidence of respiratory diseases, including pneumonia (33-36) and the gastrointestinal tract (37-39). Due to the nutrition pattern, insufficient and inadequate to age and health condition, adolescents are more likely to develop cold and nutritional diseases and have a higher risk for relapse and chronic course of the disease $(40,41)$. This is because the organism of children and adolescents responds quite sharply to any deficiency and / or imbalance of essential nutrients. In cases of untimely correction of eating disorders, the probability of delay in physical and mental development, weakening of immunity, and disorders in the activity of organs that provide homeostasis in the organism increases (42).

Increased basal metabolism and energy consumption in children and adolescents dictate the need for a special approach to the planning of their nutrition. Consumption of products that provide the organism with energy below a certain limit should not be allowed, which provides a basic energy exchange, energy consumption for digesting food, physical and mental activity. The energy expended by the body of an adolescent should be constantly compensated with food; otherwise, organism is forced to replenish the energy expended at the expense of its internal reserves (43). Therefore, it is undeniable that insufficient or excessive caloric intake of the diet has an extremely negative impact on the health of adolescents. 


\section{Proteins}

Proteins are particular important compound of nutrition of a growing organism. In an adolescent, the need for proteins in addition to age and sex is determined by increased amount of educational and physical stress, and the effect of unfavorable environmental factors. It should be emphasized that for children and adolescents, not only the amount of protein consumed with food, but also its quality, or its biological value, which is determined largely by the aminoacid composition of food proteins is important (43-45).

Inadequate intake of protein disrupts the processes of protein synthesis and decomposition, shifting it toward increased disintegration of the organism's own proteins, including enzymes. At the same time, organs and tissues, characterized by a high rate of protein renewal, in particular the intestine and the hematopoietic organs, primarily suffer. The damage of the intestinal mucosa leads to a deterioration in the absorption of food proteins in the intestine, thereby increasing the degree of protein deficiency. Impairment of protein synthesis in the bone marrow, a decrease in absorption of iron and a number of vitamins in the intestine cause oppression of hematopoiesis and the development of anemia (43). It was also found that the lack of proteins, iodine, vitamin A, folic acid, calcium, iron deficiency in the diet leads to a delay in development, an increased risk of infections and a violation of bone mineralization (28).

Reduction in the intensity of the formation of antibodies to various bacteria and viruses leads to a weakening of the body's resistance to infections. Along with this, there are significant disorders of the skin, hair, nails, and the intensity of the production of hormones decreases. Deficiency of protein at the level of the whole organism leads to a disruption in growth, physical and neuropsychological development (44, 45). Nutritional proteins also perform a protective function, increasing the body's resistance to the action of various infectious and toxic agents, neuropsychotic strain and stressful situations.

Fats are necessary in nutrition as energy and structural material. None of the fats, taken separately, can fully meet the needs of the body of children and adolescents in fatty substances. Animal fats, including milk, contain significant amounts of saturated fatty acids, one of the risk factors for development of non-infectious diseases. Vegetable fats contain many polyunsaturated fatty acids (PUFAs) and tocopherols but do not contain vitamins $A$ and $D$. It has also been established that for normal growth and development and an adequate immune response, not only a sufficient amount of PUFA in food is needed but also a correct ratio between $\omega-6$ and $\omega-3$ - PUFA, which is 10: 1 - 8: 1 .

Over the past three decades, animal fat consumption per capita has increased in developing and developed countries and the prevalence of noncommunicable diseases has increased accordingly (41). Insufficient intake of vegetables, fruits, and excess fat in food contribute to the development of overweight, dyslipidemia, arterial hypertension, anemia, cardiovascular and oncological diseases $(27,29,31)$.

\section{Carbohydrates}

Carbohydrates are the main sources of energy (15). Excess carbohydrate intake, which is more common than their deficiency, has an adverse effect on the organism, being one of the risk factors for developing excess body weight and obesity, and also having an inflammatory and allergic effects. Excess sugar and sweets in the diet, especially when consumed, not at the end of the main meals, but between them, is one of the most important causes of caries development, a decrease in appetite and prevents the consumption of foods with higher nutritional value, such as meat, milk, fish and others $(42,43)$. Excess intake of free sugars with low intake of complex carbohydrates, namely fruits and vegetables, can also contribute to the development of obesity, and diabetes mellitus $(29,30,46,47)$. 
To confirm and develop the concept of balanced nutrition, the principle of "multicomponent nutrition balance" was proposed (28), i.e. the attitude to the diet should not only be like "calories and the ratio of proteins: fat: carbohydrates", but also should take into account the necessary one-stage use of a wide range of basic components. "Without including in the control of the diet calculations for the provision of iodine or iron, we do not consider it important to care about the development of intelligence and memory. Neglecting the analysis of the provision of zinc to boys, we doom them to problems of growth, puberty and fertility. Without calculating the calcium "rations", we form juvenile osteochondropathies and osteochondrosis of the adult period of life "(28).

The deterioration of the quantitative and qualitative characteristics of nutrition largely determines not only the emergence of the most common chronic noninfectious diseases, but also the high mortality from cardiovascular diseases associated with excessive consumption of animal fats and the prevalence of this obesity. Low level of consumption of vegetables and fruits leads to a decrease in resistance to acute diseases, including colds (48-51).

\section{Vitamins and microelements}

It is now recognized that inadequate intake of micronutrients in children (vitamins, minerals) is the leading nutritional factor contributing to the aggravation of infectious pathology and the growth of noncommunicable diseases prevalence $(46,47)$. Even very small amounts of these nutrients are essential to ensure the normal growth and development of children, maintaining health. According to $\mathrm{WHO}$ and other reports, one third of humanity is at risk of developing various conditions associated with this deficiency (5052).

Deficiency of iron, iodine, zinc, and vitamin A are the most common micronutrient deficiencies described in children being contributing factors to increased mortality and morbidity in developing countries (53, 54).

Vitamins and microelements are among those indispensable biologically active substances, the deficiency of which in the body can be accompanied by dysfunction of many physiological systems $(51,52)$. Insufficient intake of vitamins adversely affects the indicators of physical and neuropsychological development of adolescents, their morbidity, academic performance, contributes to the gradual development of metabolic disorders and chronic diseases $(25,55)$.

It is possible to single out a number of anatomical and physiological features of children of school age, which determine the increased needs of children of this age group in vitamins and minerals (56):

-Continued growth and increase in body weight with a sharp acceleration of height in the puberty period (absolute increase in height is $20 \%$ of the height of an adult, an increase in body weight - about $50 \%$ of the body weight of an adult);

-Increase in muscle mass, increase in bone density (accumulation of $80-90 \%$ of genetically determined bone mass responsible for the strength of the skeleton, occurs in childhood, affecting the time of appearance of signs of osteoporosis in older age);

-The processes of differentiation of organs and tissues continue; in the pubertal period there is an intensive functional reorganization of the body, which is based on a sharp change in the functioning of the endocrine system, associated with puberty;

-There is improvement of functional interrelations and processes of regulation of the activity of organs and systems with the maximum tension of the body's regulatory systems in the adolescent period;

-Formation of higher cerebral functions determining the ability to learn is observed; changes in the psychological sphere of adolescents in the form of imbalance, increased emotional excitability and improvement in cognitive functions (abstract thinking, self-control, criticism), emotional and psychological aspects of interpersonal interactions are formed;

-The detoxifying systems of the organism mature; -Food preferences and eating habits are being formed. Deficiency of vitamins in the organism develops with the complex influence of unfavorable factors and occurs in $10-45 \%$ of the inhabitants of Russia. The situation is aggravated by irrational nutrition, acute or chronic diseases, especially the gastrointestinal tract, environmental problems in the area of residence (57, 58).

Mineral substances (macro- and microelements) that are important for the harmonious growth and development of children and adolescents include calcium, iron, iodine, zinc, sodium and fluorine. However, depending on geographical location, environmental factors and national characteristics, copper, selenium, and possibly other substances can be added to them. The problem of the supply of vitamins 
and minerals in children and adolescents is becoming increasingly important, since the growing organism is particularly sensitive to the imbalance of micronutrients. Vitamins and minerals must be delivered regularly, in full and in accordance with age-related physiological needs (59).

According to many epidemiological studies, it is in adolescent age there might be development not just temporary changes, but persistent disturbances related to the irrational structure of nutrition: micronutrient deficiency, insufficient protein content or excessive caloric intake (24-39). Food can be the source and carrier of potentially hazardous chemicals (22-23). They enter food insecurities along biological chains, in the process of agricultural production, storage, and packaging.

Scientists have scientifically proved that rational nutrition, vitamin and micro-nutrient prophylaxis in the family and in educational institutions, development and implementation of preventive programs aimed at optimizing the nutrition of children, can improve the health status of $10-15 \%$ of students with chronic diseases of the digestive system and in $75-80 \%$ of cases stabilize pathological processes (25).

Recent studies on food consumption patterns in schools demonstrated that schoolchildren consume less than $60 \%$ of recommended calories (60) and the packed home lunches children bring to school had higher energy value, high carbohydrates level, sugar 14 times higher $(95 \% \mathrm{Cl}$ $10.2-17.7)$ and saturated fat $4.7(95 \% \mathrm{Cl} 2.4-7.1)$ times higher than school offered lunch (61). A survey study on sex differences in food consumption and physical activity in children and adolescents demonstrated the higher prevalence of obesity and overweight in children of 5-9 years old (OR-1.22); female adolescents were likely to consume more often fruits and vegetables in compliance with Australian dietary guidelines (OR-1.84, 95\% Cl 1.162.93, $p=0.01$ ), than male, while male adolescents significantly more often used to drink sugar-contained beverages (62).

The solutions might include intervention in schools providing children with balanced nutrition and education of healthy food consumption (63-65). A randomized controlled study from Chile demonstrated that nutrition education and physical activity education

provided in schools are helpful in controlling obesity and overweight (63).

Several studies have demonstrated on successful application of school food programs $(64,65)$ : in Japan School Lunch program, the reference values for food served in schools includes consumption of ingredients for ages between 6-7 to 14 years: energy value between $560-850 \mathrm{kcal}$, protein $16-28 \mathrm{~g}$, fat about $20-30 \%$ of total energy of school lunch, dietary fiber 5.5=7.5. g, as microelements - sodium <2-3 g, Ca 300-470 $\mathrm{mg}$, iron -3-4 mg, vitamin A -130-210 $\mathrm{gRE}$, vitamin B-1 0.4-0.6 m, B-2- 0.4-0.6 mg, C- 20-33 mg. The program includes also collaboration of families, teachers, school physicians and dieticians aiming at healthy balanced diet, education on healthy food choices and food cultures (64). The American school lunch and breakfast programs are aligned with meals meeting following guidelines: $1 / 3$ of recommended dietary allowance of calories and nutrients - protein, vitamin $A$ and $C$, calcium and iron, $\leq 30 \%$ of calories from fat, $\leq 10 \%$ of calories from saturated fat, reduced sodium and cholesterol containing foods, increase in dietary fiber and inclusion of fluid milk (65). The review of the studies on implementation of these programs demonstrated that food insecure girls after involvement in programs become less overweight, and children participating in school meal program take higher calories than non-participants do, and there was an inverse relation between school meals intake and obesity (65).

\section{Conclusion}

Thus, providing children and adolescents with a balanced nutrition that fully satisfies the increased energy needs is one of the leading conditions for the formation of a healthy body and reduction of the risk of morbidity. In this regard, the study of the state of the actual nutrition makes it possible to carry out its timely correction and influence the formation of human health, especially in organized children's and teenage groups. The implementation of school lunch programs and education of parents and children on healthy diet is a solution to reduce effects of unbalanced nutrition on morbidity of children, though more studies are needed to estimate effects of different interventions in reduction of effects of unbalanced nutrition: malnutrition or overweight and obesity.

Peer-review: Internal and external Conflict of interest: None to declare

Authorship: F.K., M.E. and T.T. contributed equally to the preparation of manuscript

Acknowledgement and funding: None to declare 


\section{References}

1. Hasin LA, Gromiko VV, Rafalovich AB. Test for determination of physical condition level in students of 7-17 years old. Malhovka 1999; 73p.

2. European strategy "Health and development of children: from resolution to action ". 2005; 22p.

3. Lubisheva LI, Malinin AV. Investigation of health and behavior of Russian schoolchildren. Physical Culture 2004; 6: 16-21.

4. Anderson GH, Hunschede $\mathrm{S}$, Akilen R, Kubant R. Physiology of food intake control in children. Adv Nutr 2016; 7 (Suppl): 232S-40S.

5. Yakovleva TV, Baranov AA. State policy on children healthcare: problems and goals. Problems Modern Pediatr 2009; 8: 6-10.

6. Fenech MF, El-Sohemy A, Cahill L, et al. Nutrigenetics and nutrigenomics: viewpoints on current status and applications in nutrition research and dietetics practice. J Nutrigenet Nutrigenom 2011; 4: 69-89.

7. Voznesenskaya TG. Disorders of nutritional behavior and their correction in obesity. Obes Metab 2004; 2: 2-6.

8. Soliman A, De Sanctis V, Elalaily R. Nutrition and pubertal development. Indian J Endocrinol Metab 2014; Suppl 1: 39-47.

9. Dube A, Moffatt M, Davison C, Bartels S. Health outcomes for children in Haiti since the 2010 earthquake: a systematic review. Prehosp Disaster Med 2017: 1-12.

10. Meiqari L, Hoetjes M, Baxter L, Lenglet A. Impact of war on child health in northern Syria: the experience of Médecins Sans Frontières. Eur J Pediatr 2017 Dec 19. doi: 10.1007/s00431-017-3057-y.

11. Akombi BJ, Agho KE, Merom D, Renzaho AM, Hall JJ. Child malnutrition in sub-Saharan Africa: A metaanalysis of demographic and health surveys (20062016). PLoS ONE 2017; 12: e0177338.

12. Bain LE, Awah PK, Geraldine N, Kindong NP, Sigal Y, Bernard N, et al. Malnutrition in Sub - Saharan Africa: burden, causes and prospects. Pan Afr Med J 2013; 15: 120.

13. Pelletier DL, Frongillo EA, Jr., Schroeder DG, Habicht JP. A methodology for estimating the contribution of malnutrition to child mortality in developing countries. J Nutr 1994; 124 (Suppl 10): 2106S-22S.
14. Atsu, B, Guure C, Laar AK. Determinants of overweight with concurrent stunting among Ghanaian children. BMC Pediatrics 2017 17: 177.

15. WFP. World Food Summit in Rome. 1996. WFP. Rome.

16. Ogden CL, Carroll MD, Kit BK, Flegal KM. Prevalence of childhood and adult obesity in the United States, 2011-2012. JAMA 2014: 311: 806-14.

17. de Almeida MMS, Guimaraes RA, Jardim PCBV, Sousa ALL, de Souza MM. Association between arterial hypertension and nutritional status in adolescents from Goiânia, Goiás, Brazil. PLoS One 2017; 12: e0188782.

18. Arvidsson $L$, Eiben $G$, Hunsberger $M$, De Bourdeaudhuij I, Molnar D, Jilani $\mathrm{H}$, et al., and IDEFICS consortium. Bidirectional associations between psychosocial well-being and adherence to healthy dietary guidelines in European children: prospective findings from the IDEFICS study. BMC Public Health 2017; 17: 926.

19. Kaneta K. Choudhury, Manzoor A. Hanifi, Sabrina Rasheed, and Abbas Bhuiy. Gender Inequality and Severe Malnutrition among Children in a Remote Rural Area of Bangladesh. J Health Popul Nutr 2000; 18: 12330.

20. Faruque ASG, Ahmed AMS, Ahmed T, Islam MM, Hossain I, Roy SK, et al. Nutrition: Basis for healthy children and mothers in Bangladesh. ICDDR,B, Mohakhali, Dhaka 1212, Bangladesh.

21. Richardson SA. The relation of severe malnutrition in infancy to the intelligence of school-children with differing life histories. Pediatr Res 1976; 10: 57-61.

22. The Food and Agriculture Organization of the United Nations. The State of Food Insecurity in the World: How does international price volatility affect domestic economies and food security. 2011. FAO. Canada.

23. World Bank. Repositioning Nutrition as Central to Development: A Strategy for Large-Scale Action. 2006.Washington, DC. World Bank.

24. Ugolev AM. Theory of adequate nutrition and trofology. Sankt-Petersburg, Nauka 1991: 271p.

25. Tutelyan VA. Correction of micronutrient deficiency - the most important concept of healthy nutrition of population of Russia. Problems Nutr 1999; 1: 3-11. 
26. Kon IY. Nutrition of a healthy and a sick child. Moscow, RSMU 1998, 450p.

27. Vorontsov IM. Dietology of development - the most important component of preventive pediatrics and valeology of childhood. Pediatrics 1997; 3: 57-61.

28. Baranov AA, Sheplyagina LA. Problems of adolescent age. Moscow 2003; 480 p.

29. Ermolaev DO. Prognostic value of social risk factors in the development of chronic somatic pathology in children. Proceedings $2^{\text {nd }}$ Regional Scientific Forum "Mother and Child" Sochi 2008. pp 262-3.

30. Kuchma VR. Approaches to the evaluation of sanitary-epidemiological wellness level of educational institutions for children and adolescents. Hygiene Sanitary 2004; 3: 47-50.

31. Maksimova TM, Gaenko ON. Health of population and social-economic problems of society. Probl Soc Hyg Healthcare and History Med 2003; 1: 3-7.

32. Data of National Statistical Committee of Kyrgyz Republic - 2016. Available at: URL: http://www.stat.kg.

33. Barchukov VG, Salenko YA, Vyatlova OA. "Askocept" in correction of disadaptive conditions in young population with undernutrition and hypothrophy. Milit Med J 2003; 3: 71-6.

34. Mostovskii VY, Davidovich IM, Jolondz NN, Mamrovskaya TP. Course of out-of-hospital pneumonia in soldiers with hypotrophy. Milit Med J 2003; 6: 59-61.

35. Gederim VV, Gall AN, Sokolovksii VV et al. Nonspecific resistance of organism in ulcer of duodenum in military. Milit Med J 2001; 9: 50-4.

36. Novojenov VG, Luft VM, Bakulin IG, Ruseikin VM. Nutritional support of wounded and injured; state of problem. Milit Med J 2001; 8: 26-31.

37. Kalinin AV. Dynamics of anti-inflammatory cytokins in gastric ulcer associated with Helicobater Pylori infection. Milit Med 2003; 4: 62-7..

38. Krivosheev OA. Dynamics of humoral immunity in the setting of ulcer of duodenum in recruits and soldiers of the first year of service. Milit Med J 2001; 6 : 59-65.

39. Melnichenko PI. Features of epidemiology and prevention of pneumonia in military in conditions local wars and armed conflicts. Milit Med J 2001; 8: 54-61.

40. Diet, Nutrition and Prevention of Chronic Diseases. Report of a Joint WHO/FAO Expert
Consultation. WHO Technical Report Series, 2016. WHO, Geneva 2003; 25 p.

41. Onishenko GG. Social-hygienic problems of children and adolescents health conditions. Hygiene Sanit 2001; 5: 7-11.

42. Visotskii VG. Role of protein in nutrition of healthy and patient. In: Visotskii VG, Pokrovski AA, Shirina LI, editors. Textbook on dietology. Moscow, Medicine 1992; pp. 11-8.

43. Requirements in energy and protein. Report of United Consulting Expert Meeting FAO/ WHO/ UN. WHO Technical Series Reports 724. WHO, Geneva 1987: $208 p$.

44. Reeds P. Proteins and aminoacids. In: Reeds P, Beckett $P$, editors. Current knowledge in nutrition. Washington 1996: pp. 67-87.

45. Fomon SJ. Proteins. In: Fomon SJ, editor. Nutrition of normal infants. St. Louis: Mosby, 1993: pp. 121-47.

46. Emelyanova TP. Vitamins and mineral substances. Full textbook for physicians. SanktPetersburg. ID Ves 2001; 387p.

47. Martinchik AN, Baturin AK Actual consumption of energy and main nutritional components by children and adolescents of Russia in mid-90 ties. Prevention of diseases and Strengthening of Health 1998; 3: 14-5.

48. Jukovskii GS, Varlamova TA, Konstantinov VV. Trends in formation of dynamics and regional differences in epidemiology of ischemic heart disease. Cardiology 1996; 3: 8-18.

49. Atlas of health in Europe. Copenhagen, WHO Regional Office for Europe 2003; $123 \mathrm{p}$.

50. Dietary reference intakes for thiamin, riboflavin, niacin, vitamin B6, folate, vitamin B12, pantothenic acid, biotin, and choline. National Academy Press, Washington, D.C. 1998: 564 p.

51. UNICEF. Vitamin and Mineral Deficiency: A Challenge to the World's Food Companies. New York, Ottawa 2004.

52. Istomin AV, Mamchuk NP, Klepikov OV. Ecological and hygienic problems of optimization of nutrition of population. Moscow 2001; 419p. 
53. Leaf $A A$, on behalf of the $R C P C H$ Standing Committee on Nutrition. Vitamins for babies and young children. Arch Dis Child 2007; 92: 160-4.

54. Hendricks KM, Duggan C, Gallagher L, et al. Malnutrition in hospitalized pediatric patients. Current prevalence. Arch Pediatr Adolesc Med 1995; 149: 111822.

55.Tutelyan VA. Concept of optimal nutrition. Proceedings of Congress. State concept of "Health nutrition policy in Russia". Moscow 2003; pp.524-5.

56.Gorelova JY, Kizenko OA, Mosov AV, et al. Optimization of nutrition organization of children and adolescents in educational institutions. Problems Pediatr Dietol 2003; 1: 84-7.

57.Delyagin VM. Mineral and vitamin deficiency in children. Russian Pediatr J 2006; 1: 48-52.

58.Olson R. The Merck manual of diagnosis and therapy. In: Olson R, Beers M, Berkow R. The Merck manual. West Point 1999; pp. 33-58.

59.Esenamanova MK, Kochkorova FA, Sarjanova KS, Davidova LN. Recommended of food products consumption for different population groups of Kyrgyz Republic. Methodical recommendations. Bishkek, 2011; $78 p$.

60. Canteberry M, Francois S, van Hattum T, Rudov L, Carton TW. School lunch consumption 3 food service providers in New Orleans. J Sch Health 2018; 88: 93100.

61.Evans CE, Cleghorn CL, Greenwood DC, Cade JE. A comparison of British school meal sand packed lunches from 1990 20017: meta-analysis by lunch type. Br J Nutr 2010; 104: 474-87.

62. Hoare E, Dash SR, Jennings GL, Kingwell BA. Sexspecific associations in nutrition and activity-related risk factors for chronic disease: Australian evidence from childhood to emerging adulthood. Int J Environ Res Public Health 2018; 15: 214.

63.Kain J, Concha F, Moreno L, Leyton B. School-Based Obesity Prevention Intervention in Chilean Children: Effective in Controlling, but not Reducing Obesity. J Obes 2014; doi: 10.1155/2014/618293.

64. Tanaka N, Miyoshi M. School lunch program for health promotion among children in Japan. Asia Pac J Clin Nutr 2012; 21: 155-8.

65. Hopkins LC, Gunther C. A historical review of changes in nutrition standards of USDA child meal programs relative to research findings on the nutritional adequacy of program meals and the diet and nutritional health of participants: implications for future research and the summer food service program. Nutrients 2015; 7: 10145-67. 